\title{
Soberanía popular y concepción fiduciaria de los representantes públicos en Maximilien Robespierre
}

\section{Popular sovereignty and fiduciary conception of public representatives in Maximilien Robespierre}

PABLO SCOTTO*

\begin{abstract}
Resumen: En su discurso del 10 de mayo de 1793 sobre la Constitución, Robespierre combina una concepción fiduciaria de los representantes públicos con una defensa de las virtudes de la democracia, el único sistema político en el que los gobernantes, al ser parte del pueblo, tienen los mismos intereses que este. Es esta defensa de la soberanía popular, así como de la primacía del poder legislativo, lo que constituye la esencia de su "economía política popular", una expresión que toma de Rousseau. Para Robespierre, solamente esta clase de economía es compatible con una República cuyo primer objetivo sea la garantía de los derechos naturales del hombre.

Palabras clave: soberanía popular, democracia, relaciones fiduciarias, representación política, economía política, Robespierre, Rousseau.
\end{abstract}

\begin{abstract}
In his 10th May 1793 speech on the Constitution, Robespierre combines a fiduciary conception of public representatives with a defence of the virtues of democracy, the only political system in which the rulers, being part of the people, have the same interests as the latter. It is this defence of popular sovereignty, as well as of the primacy of the legislative power, what constitutes the essence of his "popular political economy", an expression he takes from Rousseau. For Robespierre, only this kind of economy is compatible with a Republic whose first objective is to guarantee the natural rights of man.

Keywords: popular sovereignty, democracy, fiduciary relations, political representation, political economy, Robespierre, Rousseau.
\end{abstract}

\section{Introducción}

Uno de los conflictos políticos más importantes de la Revolución Francesa gira en torno a la forma de entender la relación entre el pueblo y sus representantes públicos. Dejando a un lado a los contrarrevolucionarios de distinto signo, la oposición principal se produce

Recibido: 29/05/2020. Aceptado: 17/06/2020. Cómo citar este articulo: Scotto, P. (2020). Soberanía popular y concepción fiduciaria de los representantes públicos en Maximilien Robespierre. Daimon. Revista Internacional de Filosofía, (81), 83-98. https://doi.org/10.6018/daimon.429931

* Investigador en el Departamento de Ciencia Política, Derecho Constitucional y Filosofía del Derecho de la Universidad de Barcelona (pablo.scotto.benito@ub.edu). Sus líneas de investigación principales son la filosofía política contemporánea y la historia del socialismo. Entre sus publicaciones recientes: Scotto, P. (2019), "Thinking the future of work through the history of right to work claims", Philosophy \& Social Criticism, OnlineFirst, DOI: 10.1177/0191453719860220; Scotto, P. (2020), "El derecho a la asistencia pública en las Constituciones francesas de 1791 y 1793”, Historia Constitucional, artículo aceptado para su publicación en el número 21 de la revista. 
entre los partidarios de un "sistema representativo" y los defensores de la soberanía popular. Aunque las cosas son en realidad más complejas, se puede decir que los primeros entienden la representación como una delegación de responsabilidad, mientras que los segundos supeditan cualquier decisión de los diputados a su aprobación ulterior por parte del pueblo soberano. Es sobre todo entre estos últimos que es habitual encontrar un lenguaje de tipo fiduciario: a) el pueblo es el principal, y no deja de serlo en ningún momento; b) las autoridades públicas, más que representantes, son agentes o mandatarios al servicio del pueblo, y en consecuencia deben rendir cuentas de sus acciones ante el mismo de forma periódica; c) la confianza otorgada por el pueblo a sus mandatarios, que es aquello en lo que se basa el poder de estos últimos, puede ser revocada por aquel de forma unilateral. ${ }^{1}$

No cabe duda de que el abate Sieyes es uno de los teóricos más lúcidos del "sistema representativo". ${ }^{2}$ Robespierre, por su parte, es seguramente el dirigente revolucionario que ha defendido el principio de la soberanía popular de forma más clara y consecuente. Este artículo está centrado en este último autor. No pretendo abordar, pues, la totalidad de las cuestiones que tienen que ver con la representación política en la Revolución Francesa. ${ }^{3}$ Ni tan siquiera aspiro a dar una visión de conjunto sobre la posición de Robespierre a este respecto. ${ }^{4}$ Simplemente quiero poner de relieve dos cuestiones: a) el vínculo que Robespierre establece entre su concepción fiduciaria de los representantes públicos y las virtudes de la democracia: esto es, la virtud del sistema político democrático y la virtud del propio demos; b) la forma en que lo anterior, unido a la primacía del poder legislativo, en Robespierre desemboca en la defensa de una "economía política popular".

\section{El contenido del mandato}

Antes de tratar las dos cuestiones señaladas, conviene precisar cuál es, para Robespierre, el principal mandato de los diputados elegidos para formar parte de las diferentes asambleas revolucionarias: constituir una nueva comunidad política, basada en los principios contenidos en la Declaración de derechos del hombre y del ciudadano. Esta no es, por supuesto, una idea original de Robespierre. La concepción de la Declaración como un nuevo contrato social es una suerte de sentido común entre los revolucionarios de 1789. La idea es que todos los seres humanos comparten una serie de "derechos naturales e imprescriptibles", cuya conservación o garantía es la "finalidad de toda asociación política". Derechos naturales del hombre, por un lado, y derechos del ciudadano, por el otro, entendidos estos últimos como la trasposición de los primeros al estado social.

1 Sobre la presencia de este lenguaje fiduciario en la filosofía política de Locke, véase: Domènech $(2009,19)$ y Mundó (2017, 442).

2 Como muestra de esa complejidad a la que acabo de hacer referencia, baste con señalar que el abate, a pesar de contraponer su sistema representativo a la democracia (Sieyes, 1985, 236), emplea un lenguaje con una clara impronta fiduciaria $(1789$ a, 36; 1789b, 21). En efecto, su elaborada teoría de la representación política está en una suerte de punto intermedio entre los partidarios del mandato imperativo y quienes defienden la alienación de la soberanía (véase Máiz, 2007, 157-196).

3 Para una magnífica introducción al problema - y como parte de una más amplia reflexión sobre los principios políticos contenidos en la Declaración de derechos de 1789-, véase García Manrique (2001, 321-329).

4 Para esto, véase el ya citado libro de Bosc (2019), así como Rudé (1976, 95-128). Para una comparación entre las teorías fiduciarias del poder político en Robespierre y Jefferson, véase Laín (2020, 14-16, 23-24 y 29). 
Lo que sí es característico de los montagnards, y de Robespierre en particular, es la radicalidad con la que asumen y pretenden realizar los mencionados principios. En las páginas que siguen, intentaré mostrar de qué manera esta radicalidad va ligada a una forma concreta de entender la representación política. Robespierre no se cansa de repetir en sus discursos que los representantes públicos son comisarios del pueblo y que, en cuanto tales, tienen la misión de poner en obra los derechos reconocidos en 1789, a fin de que la Declaración no se convierta en papel mojado.

Al establecer este vínculo entre derechos y mandato popular, Robespierre no está haciendo otra cosa que llevar hasta sus últimas consecuencias los principios políticos contenidos en la propia Declaración. El artículo 3 dice que la soberanía reside esencialmente en la nación. El artículo 6 especifica que todos los ciudadanos tienen derecho a colaborar en la formación de la ley, sea personalmente, sea por medio de sus representantes; y declara, además, la igual elegibilidad para todos los cargos públicos. El artículo 15 establece que los agentes públicos tienen la obligación de rendir cuentas de su administración ante sus electores.

Si decimos que Robespierre lleva hasta sus últimas consecuencias estos principios es porque su propio proyecto de Declaración - que presenta ante la Convención el 24 de abril de 1793 - puede leerse como un esfuerzo por precisar y desarrollar (radicalizar, si se quiere), en una fase más madura de la Revolución, los derechos que habían sido proclamados en 1789.

El mantenimiento de los derechos naturales - entre los que Robespierre destaca la existencia material y la libertad- es, de nuevo, el fin de toda asociación política. Vuelven a aparecer, por su parte, esos principios políticos a los que ya nos hemos referido. El artículo XIV es una afirmación clara y rotunda de la soberanía popular, que se vincula a la concepción de los funcionarios públicos como comisarios o mandatarios del pueblo, revocables en todo momento por este. El artículo XXI establece la igual elegibilidad para los cargos públicos. El XXII, el igual derecho de todos los ciudadanos a participar en el nombramiento de los mandatarios, y a participar en la propia elaboración de las leyes. El artículo XXXIV afirma que los mandatarios deben rendir cuentas de su gestión ante el pueblo.

También se aprecian algunas novedades importantes. Hay un artículo, en particular, que tiene una formulación muy llamativa, y cuyo significado no se alcanza a comprender si no se pone en relación con su concepción fiduciaria del poder político (Domènech, 2015, 76):

XIX. En todo estado libre, la ley debe defender, sobre todo, la libertad pública e individual contra el abuso de autoridad de quienes gobiernan.

Toda institución que no suponga que el pueblo es bueno, y el magistrado corruptible, está viciada (Robespierre, 1958 [1793], 9, 467).

El presente texto se propone ahondar en el significado de esta disposición. En lo que sigue intentaré explicar, pues, cuáles son las precauciones que, a fin de defender la libertad, la ley debe establecer contra los posibles abusos del gobierno. Intentaré mostrar, sobre todo, la forma en que Robespierre vincula estas precauciones con la suposición de que el pueblo es bueno. Una vez hecho esto, que es lo que constituye el centro del artículo, me referiré brevemente a la cuestión de la "economía política popular", que en Robespierre - aunque ello le pueda resultar paradójico al lector contemporáneo - tiene mucho que ver con todo lo anterior. 


\section{El pueblo es bueno ${ }^{5}$}

El discurso del 10 de mayo de 1793 sobre la Constitución es el lugar en el que Robespierre establece el mencionado vínculo entre una concepción fiduciaria de las autoridades públicas y la suposición de que el pueblo es bueno. Al mismo tiempo, es la única ocasión en la que se sirve de la expresión "economía política popular" (Bosc, 2019, 144). Vayamos primero con el vínculo. Robespierre empieza parafraseando a Rousseau:

El hombre ha nacido para el bienestar [bonheur] y para la libertad, pero en todas partes es esclavo y desgraciado. La sociedad tiene como objetivo la conservación de sus derechos y la perfección de su ser, y en todas partes la sociedad lo degrada y lo oprime (Robespierre, 1958 [1793], 9, 495).

Los derechos naturales del hombre proclamados en 1789 impelen al legislador a darle a la Revolución todas las vueltas de tuerca que sean necesarias para que aquellos se conviertan en una realidad efectiva. Es necesario fundar la sociedad sobre nuevas bases, insertar en todas las instituciones públicas una nueva política, enemiga de todo privilegio y basada en la libertad y felicidad del pueblo:

Hasta aquí, el arte de gobernar no ha sido más que el arte de despojar y subyugar a la mayoría en beneficio de la minoría, y la legislación, el medio de convertir estos atentados en sistema. Los reyes y los aristócratas han hecho muy bien su trabajo: ahora debéis hacer el vuestro, es decir, debéis hacer felices [heureux] y libres a los hombres a través de las leyes (Robespierre, 1958 [1793], 9, 495).

Asegurar los derechos de todos requiere controlar tanto el dominium entre particulares como el imperium entre el soberano y sus gobernados:

Dar al gobierno la fuerza necesaria para que los ciudadanos respeten siempre los derechos de los ciudadanos, y hacer que el propio gobierno no pueda violarlos nunca: ahí está, en mi opinión, el doble problema que el legislador debe intentar resolver (Robespierre, 1958 [1793], 9, 495).

Los representantes públicos deben ocuparse de estas dos tareas y dejar de temer los supuestos excesos del pueblo:

He oído hablar mucho de anarquía desde la revolución del 14 de julio de 1789, y sobre todo desde la revolución del 10 de agosto de 1792. Pero yo afirmo que la

5 Sobre el concepto de "pueblo" en Robespierre, véase el análisis de Geffroy $(1989,179-193)$. Su tesis es que existe una ambigüedad entre el "pueblo-clase", el pueblo identificado con los pobres, y el "pueblo-nación", el pueblo en tanto que comunidad política. Como muy acertadamente señala la autora, no es una ambigüedad exclusiva de Robespierre, sino intrínseca al propio concepto. Pueblo, en efecto, está siempre a medio camino entre lo social y lo político: su invocación remite a la parte más numerosa y más pobre de la población, pero también, y al mismo tiempo, al conjunto de los ciudadanos, a la totalidad de la nación. 
anarquía no es en absoluto la enfermedad que sufren los cuerpos políticos, sino el despotismo y la aristocracia (Robespierre, 1958 [1793], 9, 495-496).

Aparece aquí ese cuerpo enfermo por los malos humores de la aristocracia del que hablaba Sieyes al inicio de la Revolución (1970 [1789], 218), solo que ahora la enfermedad no viene solamente de los que quieren mantener los viejos privilegios, sino también de aquellos que traicionan, o pretenden realizar solamente de forma parcial, los principios de 1789. Siguiendo con el argumento, afirma Robespierre:

Los males de la sociedad nunca vienen del pueblo, sino del gobierno. ¿Cómo podría ser de otro modo? El interés del pueblo es el bien público. El interés del hombre en el poder es un interés privado. Para ser bueno, el pueblo no necesita más que preferirse a sí mismo frente a lo que le es extraño [se préférer lui-même à ce qui n'est pas lui]. Para ser bueno, el magistrado debe sacrificarse a sí mismo en favor del pueblo (Robespierre, 1958 [1793], 9, 496).

La afirmación de que el pueblo es bueno, o la idea de que los males de la sociedad no vienen nunca del pueblo, no significan que los gobernados, los pobres, sean todos ellos, y sin excepción, individuos virtuosos. Robespierre no pretende que el pueblo llano sea un pueblo de ángeles. No cae en ese error que Spinoza atribuye a los filósofos al comienzo de su Tratado político, quienes "conciben a los hombres no como son, sino como ellos quisieran que fueran", y en consecuencia no idean:

[...] una política que pueda llevarse a la práctica, sino otra, que o debería ser considerada como una quimera o sólo podría ser instaurada en el país de Utopía o en el siglo dorado de los poetas, es decir, allí donde no hacía falta alguna (Spinoza, 2013 [1675-1677], 98).

No cabe duda de que la política de Robespierre es indisociable de la moral, así como de la tradición humanista: es "una política de la filosofía", surgida de la filosofía, por emplear la expresión de Georges Labica (2005). Impregnada del espíritu de Rousseau, para quien "el hombre es bueno por naturaleza", está muy alejada del pesimismo antropológico de Hobbes, así como de las intrigas palaciegas del Maquiavelo de El Príncipe. En cualquier caso, no es una política "filosófica", quimérica, aquejada de ese utopismo ingenuo al que hace referencia Spinoza.

Si estamos situados en el mundo real, en el que hay virtud pero también corrupción, ¿qué significa exactamente que los males sociales nunca vienen del pueblo? Quiere decir que, precisamente porque no vivimos en el siglo dorado de los poetas, la mejor manera de que los gobernantes cumplan adecuadamente su función es que todos sean, a la vez, gobernantes y gobernados. Si los gobernantes están por encima de los gobernados, aquellos no tendrán ningún interés en buscar el bien común, y solamente serán honestos si renuncian a su interés particular, si se convierten en mártires al servicio de lo público. Si quien gobierna es el pueblo en su conjunto, su interés particular coincidirá con el interés general; para ser virtuoso, le bastará con no ser tan estúpido como para traicionarse a sí mismo. 
"El interés del pueblo es el interés general, el de los ricos es el interés particular" (Robespierre, 1952 [1791], 7, 166), había afirmado ya en su discurso de abril de 1791 sobre el sufragio censitario. Si, como enseña Rousseau, la virtud en política consiste en que la voluntad particular se adecúe a la voluntad general, se sigue de ello que solo el pueblo es bueno o virtuoso. Es decir: que solo extendiendo el número de gobernantes hasta que coincidan con el número de gobernados es concebible, dada la naturaleza no angelical del hombre, que los gobernantes no se preocupen únicamente de sus intereses particulares.

Al situar el problema en este terreno, Robespierre pretende remover ese enraizado prejuicio según el cual un gobierno en el que el pueblo participa de forma activa conduce necesariamente al exceso y al descontrol. Esta participación es, al contrario, la verdadera garantía de que el bien común esté situado en el centro de la comunidad política. Ahora bien, ¿está realmente capacitado el pueblo para gobernarse a sí mismo? ¿Puede identificar sin ayudas externas el interés general? ¿No necesita acaso a las clases esclarecidas para instruirlo y para dirigirlo por la senda correcta? En efecto, la estupidez y la corrupción moral de los pobres han sido, desde Grecia, los principales argumentos que se han esgrimido en contra de la democracia. No faltan historias para nutrir la leyenda, como la de Arístides el justo: en la asamblea que le condenará al ostracismo, un campesino analfabeto le pide ayuda para escribir el nombre de su elegido, resultando ser el propio Arístides, de quien dice no soportar su buena fama. O como la de esos expertos en el visionado de sombras que, encerrados en el fondo de la caverna, matarían si pudieran al filósofo que quiere enseñarles la luz. Robespierre responde pasando al ataque:

Si me dignase a responder a los prejuicios absurdos y bárbaros, haría observar que son el poder y la opulencia los que hacen nacer el orgullo y todos los vicios; que el trabajo, la mediocridad y la pobreza son los guardianes de la virtud; que los deseos del débil no tienen otro objeto que la justicia y la protección de las leyes benéficas [bienfaisantes]; que no aprecia más que las pasiones de la honestidad, mientras que las pasiones del hombre poderoso tienden a elevarse por encima de las leyes justas, o a crear leyes tiránicas; diría, en definitiva, que la miseria de los ciudadanos no es otra cosa que el crimen de los gobiernos (Robespierre, 1958 [1793], 9, 496).

Ya no es solo que la participación del pueblo sea la mejor manera de asegurar que el interés de los gobernantes coincida con el interés general, sino que, además, ese pueblo al que tanto se ha despreciado es más virtuoso que los ricos y los poderosos. Dicho con otras palabras: el pueblo es bueno, desde un punto de vista político, en un doble sentido. Es bueno tomado en su conjunto, porque su participación en lo público es la única garantía de que el interés de los gobernantes coincida con el de los gobernados. Es bueno, además, si se tienen en cuenta los individuos que lo componen: en general, el estilo de vida de los pobres hace que su carácter sea más acorde con el interés general que el de las gentes acomodadas. Los pobres trabajan, son austeros y, en general, no quieren otra cosa que vivir sus vidas en paz, mientras que los ricos están acostumbrados a sentirse por encima de la ley, a mandar y a intrigar en la búsqueda de su interés particular. Los pobres son virtuosos en su vida privada, y eso les predispone a la virtud pública, que consiste en la 
búsqueda del interés general, en el amor a las leyes, a la República, a la igual libertad; en la pasión por realizar, en definitiva, los derechos naturales del hombre.

El discurso de Robespierre está centrado en la primera de las cuestiones señaladas (democracia como sistema político virtuoso), que sin embargo se entrecruza constantemente con la segunda (pobres como ciudadanos virtuosos). Es comprensible que así sea: una defensa del gobierno del demos basada únicamente en consideraciones relacionadas con el correcto diseño institucional no está en grado a responder a objeciones como la de Platón. La democracia es el mejor sistema político porque permite que los gobernantes, al ser parte del pueblo, tengan sus mismos intereses, pero ¿de qué serviría todo ello si el pueblo fuera, como lo han pretendido los aristócratas de todas las épocas, irremediablemente estúpido y mezquino? Es para salvar esta crítica que Robespierre entra, un poco a regañadientes ("Si me dignase a responder..."), en la cuestión de la virtud de los ciudadanos. Ya no es solo que las instituciones deban suponer que el pueblo es bueno para no estar viciadas; es que, además, el pueblo es realmente más virtuoso que aquellos que lo han gobernado hasta ahora.

Esto no quiere decir que haya que glorificar las virtudes del pueblo, como ya se había encargado de precisar Robespierre en un discurso en contra de la guerra impulsada por Brissot, en enero de 1792:

Habéis dicho que os ha sorprendido oír a un defensor del pueblo calumniar y envilecer al pueblo. Ciertamente no me esperaba semejante reproche. En primer lugar, sabed que no soy un defensor del pueblo. Jamás he aspirado a conseguir ese título fastuoso. Soy del pueblo, nunca he sido otra cosa y no quiero ser otra cosa. Desprecio a cualquiera que pretenda ser algo más ${ }^{6}$ (Robespierre, 1954 [1792], 8, 89).

Respetar al pueblo no es invocar su nombre frente a los abusos de los poderosos, sino sentirse parte del mismo, criticándolo si se equivoca, como el sabio hace consigo mismo. Robespierre vuelve a citar a Rousseau:

'El pueblo quiere [veut] siempre el bien, pero no siempre lo ve [voit]'. Para completar la teoría de los principios de los gobiernos, sería suficiente con añadir: los mandatarios del pueblo ven a menudo el bien, pero no siempre lo quieren. El pueblo quiere el bien, porque el bien público es su interés, porque las buenas leyes son su salvaguardia. Sus mandatarios no lo quieren siempre, porque quieren usar la autoridad que el pueblo les confía en provecho de su orgullo (Robespierre, 1954 [1792], 8, 90).

Al pueblo le puede faltar instrucción, y puede cometer errores, pero tiene tendencia a querer el bien de todos, ya que ese es su interés. Nadie está más interesado que el pobre en el buen funcionamiento del país: le va la vida en ello. Los gobernantes pueden estar muy instruidos y ser capaces de entender fenómenos políticos complejos, pero no siempre quieren asegurar el bienestar del pueblo, porque no forman parte de él.

6 En el discurso sobre la Constitución que estamos analizando, afirma: "No hay más que un Tribuno del pueblo que yo pueda admitir: el propio pueblo" (Robespierre, 1958 [1793], 9, 500). 
Y es que el bien, en moral y en política, no tiene que ver únicamente con la posesión de una serie de facultades intelectuales, como sabemos desde Aristóteles. El bien no es la verdad. Es algo que tiene que ver con la acción, y por lo tanto no depende únicamente de la razón, sino también de las pasiones, las costumbres y los intereses. Lo relevante en política no es tanto la posesión de vastos conocimientos, sino ese buen sentido que, como dice Descartes al principio del Discurso del método (en su caso, no sin cierta ironía), está repartido por igual entre todos los hombres.

El pueblo siente más vivamente, y ve mejor, todo lo que se refiere a los primeros principios de la justicia y de la humanidad que la mayoría de aquellos que se separan de él. Su buen sentido a este respecto es generalmente superior al espíritu de las gentes capaces [habiles gens]. Pero no tiene la misma aptitud para desembrollar los rodeos de la política artificiosa que ellos emplean para engañarlo y subyugarlo, y su bondad natural le dispone para ser víctima de los charlatanes políticos (Robespierre, 1954 [1792], 8, 90).

Las intrigas palaciegas requieren astucia y disimulo, la justificación de medidas que perjudican a la mayoría es imposible sin el dominio de la sofística, el comando de ejércitos solo está al alcance de quienes están versados en el arte de la guerra. El pueblo no posee estas cualidades, pero no entiende peor que los notables, ni siente menos en su corazón, todo aquello que gira en torno a la calificación de las acciones como justas o injustas, como conformes o no a los derechos naturales de la humanidad.

Aclaradas las razones de fondo que sustentan la defensa de la democracia en Robespierre, y que no tienen que ver con la defensa naíf de las virtudes del pueblo, volvamos al discurso de mayo de 1793. Para Robespierre, igual que para los sans-culottes, los mandatarios son servidores del pueblo, y en consecuencia "el primer objetivo de toda constitución debe ser defender la libertad pública e individual contra el propio gobierno" (Robespierre, 1958 [1793], 9, 496). Todo lo contrario de lo que se ha hecho hasta ahora, que es tomar precauciones infinitas contra la revuelta del pueblo, y ninguna para controlar el poder de los gobernantes. Esto incluye a las élites revolucionarias, que - a pesar de su nuevo lenguaje - han seguido considerando al pueblo como sinónimo de descontrol e insensatez, y a los mandatarios como esencialmente sabios y virtuosos. Al hacerlo, han perpetuado el despotismo. Y el despotismo - todo lo ilustrado que se quiera - es incompatible con los derechos naturales del hombre. Un esclavo, por muy bien que sea tratado, no es un hombre libre.

Decía Diderot al respecto:

Todo gobierno arbitrario es malo; no exceptúo el gobierno arbitrario de un amo [maître] bueno, firme, justo e ilustrado [éclairé].

Este amo acostumbra a respetar y a querer a un amo, sea el que sea.

Priva a la nación del derecho a deliberar, de querer o no querer, de oponerse, de oponerse incluso al bien.

El derecho a oponerse me parece, en una sociedad de hombres, un derecho natural, inalienable y sagrado. 
Un déspota, aunque fuera el mejor de los hombres, al gobernar a su antojo [selon son bon plaisir], comete siempre un crimen. Es un buen pastor que reduce a sus súbditos a la condición de animales; al hacerles olvidar el sentimiento de la libertad - sentimiento tan difícil de recobrar una vez perdido-, les procura un bienestar [bonheur] de diez años que pagarán con veinte siglos de miseria (Diderot, 1995 [1773], 3, 275).

Siguiendo esta línea, Robespierre llega a la conclusión de que la futura Constitución debe reconocer lo siguiente:

Que el pueblo es bueno y sus delegados son corruptibles; que es dentro de la virtud y de la soberanía del pueblo donde hay que buscar el freno [préservatif] contra los vicios y el despotismo del gobierno (Robespierre, 1958 [1793], 9, 498).

Es entonces cuando extrae, a partir de esta defensa de la soberanía popular, una serie de principios políticos. Señala, por ejemplo, que el control del pueblo sobre sus representantes debe anteceder a los contrapesos que se establezcan entre los distintos poderes del Estado. Querer moderar el poder de los magistrados solamente a través de otros magistrados es, nos dice, una ilusión. El equilibrio ficticio entre los poderes que resulta de ello no es otra cosa que una coalición de intereses contra el pueblo.

¿Qué nos importan las combinaciones que equilibran la autoridad de los tiranos? Lo que hay que hacer es extirpar la tiranía. No es en las querellas entre sus amos [maîtres] donde los pueblos deben buscar el alivio de respirar unos instantes. Es en su propia fuerza donde hay que situar la garantía de sus derechos (Robespierre, 1958 [1793], 9, 499).

Propone, a continuación, un diseño institucional en el que el poder legislativo y el ejecutivo están cuidadosamente separados, los mandatos son breves, la administración está descentralizada y el pueblo puede criticar, controlar y revocar a los servidores públicos. Lejos del pretendido centralismo jacobino al que se le suele asociar, considera que el verdadero espacio público no debe estar situado en un Estado separado de la sociedad, sino inserto en el seno de la propia sociedad civil:

Huid de la manía antigua de los gobiernos de querer gobernar demasiado. Dejad a los individuos, dejad a las familias el derecho a hacer aquello que no perjudica a los demás. Dejad a las municipalidades el poder de regular ellas mismas sus propios asuntos, en todo aquello que no se refiere a la administración general de la república. En una palabra, devolved a la libertad individual todo aquello que no pertenece naturalmente a la autoridad pública, y habréis dejado mucho menos espacio a la ambición y a lo arbitrario (Robespierre, 1958 [1793], 9, 501-502).

Ahora bien: este "dejar hacer" no es equiparable al de los fisiócratas. La libertad en la sociedad civil no se garantiza sola. Las instituciones deben facilitar la participación de todos en la cosa pública: 
¡Qué importa que la ley rinda un homenaje hipócrita a la igualdad de derechos si la más imperiosa de todas las leyes, la necesidad, fuerza a la parte más sana y numerosa del pueblo a renunciar a ella! Que la patria indemnice al hombre que vive de su trabajo cuando asiste a asambleas públicas. Que remunere con un salario, por la misma razón y de forma semejante, a todos los funcionarios públicos. Que las reglas de las elecciones y las formas de las deliberaciones sean tan simples y resumidas como sea posible. Que los días de las asambleas sean fijados en las épocas más cómodas para la parte laboriosa de la nación (Robespierre, 1958 [1793], 9, 506-507).

Robespierre resume estas directrices a insertar en la futura Constitución con una expresión que toma, de nuevo, de Rousseau:

Con ello, habréis resuelto el problema, aún incierto, de la economía [política] ${ }^{7}$ popular: colocar en la virtud del pueblo y en la autoridad del soberano el contrapeso necesario a las pasiones del magistrado y a la tendencia del gobierno a la tiranía (Robespierre, 1958 [1793], 9, 507).

A primera vista, puede resultar sorprendente que se hable de economía política en un discurso sobre la Constitución. A la luz de lo que llevamos dicho, puede entenderse un poco mejor. La clave para entender el pasaje está en las dos oposiciones que establece Robespierre, y que están ya en ese párrafo en cursiva que hemos citado antes: la virtud y la soberanía del pueblo frente a los vicios y el despotismo del gobierno. Por un lado, la virtud del pueblo se opone a las pasiones del magistrado. Como ya hemos explicado: la democracia es la única garantía de que el interés general prime sobre los intereses particulares de los gobernantes. Por el otro, la autoridad del soberano, es decir, del pueblo, se opone a la tendencia del gobierno a la tiranía. Es decir: tanto la legislación como la propia ejecución de las leyes deben estar al servicio del pueblo, y deben estar, incluso, bajo su control directo, al menos en "todo aquello que no se refiere a la administración general de la república". Solo así se podrá evitar que los gobernantes se conviertan en tiranos.

En cualquier caso, para entender plenamente el sentido del párrafo, y especialmente esta segunda oposición, lo mejor es acudir a Rousseau, de quien Robespierre toma, como decíamos, la expresión "economía política popular". ${ }^{8}$

\section{El cerebro y el corazón}

El artículo "Économie ou CEconomie" (1755) de la Enciclopedia de Diderot y d'Alembert corre a cargo de Jean-Jacques Rousseau. En esta entrada, el ginebrino establece una distinción que es fundamental para entender el texto de Robespierre. La economía política, dice,

7 He añadido la palabra entre corchetes, en base a Robespierre (2007, 11, 455). Es Florence Gauthier quien ha llamado la atención sobre la omisión del adjetivo "política" en las Obras completas de Robespierre (Gauthier e Ikni, 1988, 112).

8 Para un análisis del significado que Robespierre le otorga a esta fórmula, complementario al que vamos a presentar aquí, véase Bosc (2019, 141-178). 
es parte del gobierno, del poder ejecutivo, y únicamente puede obligar a los particulares. Solo el soberano, continúa, tiene poder legislativo, y puede obligar, en consecuencia, al cuerpo de la nación. De esto se sigue que los objetivos del poder ejecutivo - un poder del que la economía política forma parte - son distintos a los objetivos del poder legislativo:

Así como el primer deber del legislador consiste en conformar las leyes a la voluntad general, la primera regla de la economía pública consiste en que la administración sea conforme a las leyes (Encyclopédie, 1755, 5, 340).

Los legisladores tienen el deber de no anteponer su voluntad particular a la voluntad general. El ejecutivo, en cambio, tiene el deber de no inmiscuirse en el terreno reservado a los legisladores. Debe limitarse a administrar, conforme a lo establecido por las leyes. Dicho brevemente: la gestión económica está subordinada a las decisiones políticas. Rousseau explica esto con una metáfora corporal:

El cuerpo político, tomado individualmente, puede ser considerado como un cuerpo organizado, vivo, semejante al del hombre. El poder soberano representa la cabeza. Las leyes y las costumbres son el cerebro, base de los nervios y sede del entendimiento, de la voluntad y de los sentidos, cuyos órganos son los jueces y magistrados. El comercio, la industria y la agricultura son la boca y el estómago, que organizan la subsistencia común. Las finanzas públicas son la sangre, que una sabia economía, desempeñando las funciones del corazón, propulsa de nuevo, distribuyendo por todo el cuerpo el alimento y la vida. Los ciudadanos son el cuerpo y las extremidades, que hacen moverse, vivir y trabajar a la máquina, de tal suerte que, si el animal goza de buena salud, no se puede lesionarlo en alguna de sus partes sin que inmediatamente la impresión dolorosa llegue al cerebro (Encyclopédie, 1755, 5, 338).

El soberano, el que tiene el poder de decidir, es la cabeza. Quienes toman las decisiones no son personas particulares, sino las leyes: ellas son el cerebro. Estas leyes se comunican con el exterior a través de los órganos de los sentidos. La metáfora funciona bien para explicar la función de los magistrados, que deben tener buena vista, oído, tacto y olfato para detectar y abordar los problemas de la sociedad, pero no tanto para ilustrar la función de los jueces, que son más bien, como dice Montesquieu, la boca que pronuncia las palabras de la ley (Montesquieu, 1824 [1748], 1, XI.6, 320). Los diferentes trabajos de la nación son la boca que traga las materias primas, las digiere en el estómago y las hace pasar a la sangre para su distribución. Las finanzas públicas son la sangre que hace posible que los productos de la industria lleguen efectivamente a todos los rincones del cuerpo político. La economía política es el corazón que bombea esa sangre. El tronco y las extremidades, añade Rousseau, los forman el conjunto de los ciudadanos, sin excepción. Ninguno ocupa una posición privilegiada con respecto a los demás. Cualquier daño infligido contra un miembro del cuerpo político, sea rico o pobre, provoca una reacción en el cerebro: la ley es igual para todos.

Lo que me interesa destacar de la metáfora de Rousseau es que la soberanía está claramente separada de quienes ostentan los cargos públicos. La ley, y no una persona o un grupo de personas, es el cerebro del cuerpo político. Los jueces y magistrados son meros 
intermediarios entre el cerebro y el exterior, y no tienen capacidad de decisión fuera de los márgenes marcados por las leyes y las costumbres. Sucede exactamente lo mismo con la economía política: debe adecuarse a los dictados del poder legislativo. Su función es vital, pero mecánica. Oponiéndose a los fríos cálculos de la economía culta, que hace balance de pérdidas y beneficios mientras el pueblo se muere de hambre, Rousseau identifica la economía con el corazón: su función debe limitarse a asegurar, con ardor y sensibilidad, que el bienestar llegue tanto a la cabeza como a la punta de los dedos del pie.

Una vez que ha dejado claro que la economía y el gobierno deben estar al servicio de las leyes, al servicio de la voluntad general, Rousseau se pregunta por el origen y la finalidad de dichas leyes. ¿Deben ser elaboradas por los dirigentes públicos o por el pueblo? ¿Deben atender al interés de los primeros o al del segundo? Es entonces cuando establece la distinción entre economía popular y economía tiránica, que después retomará Robespierre:

Al establecer la voluntad general como primer principio de la economía pública y como regla fundamental del gobierno, no he creído necesario examinar seriamente si los magistrados pertenecen al pueblo o el pueblo a los magistrados, ni si en los asuntos públicos se debe atender al bien del estado o al de los dirigentes. Hace ya tiempo que esta cuestión ha sido decidida de una manera en la práctica, y de otra distinta según la razón; en general, sería una gran locura esperar que aquellos que de hecho son los amos [maîtres] prefirieran un interés distinto al suyo. Parecería adecuado, entonces, dividir la economía pública en popular y tiránica. La primera es la propia de todo estado en el que existe, entre el pueblo y los dirigentes, unidad de interés y de voluntad; la otra existirá necesariamente allí donde el gobierno y el pueblo tengan intereses diferentes y, por consiguiente, voluntades opuestas. Las máximas de esta última han sido inscritas en los archivos a lo largo de la historia y en las sátiras de Maquiavelo. Las otras no se encuentran más que en los escritos de los filósofos que tienen la osadía de reclamar los derechos de la humanidad (Encyclopédie, 1755, 5, 339).

El despotismo - aunque se vista con ropajes ilustrados - es la forma en que se ha resuelto en la práctica la cuestión sobre sobre quién debe participar en el poder legislativo: leyes en interés del pueblo elaboradas por déspotas, todo para el pueblo pero sin el pueblo. La razón, en cambio, nos dice que es imposible que los déspotas, por muy buenos que sean, prefieran un interés distinto al suyo propio.

Volvamos al discurso de Robespierre sobre la Constitución. Ahora se entenderá mejor el párrafo en el que nos habíamos quedado. Hay dos cuestiones a aclarar. La primera tiene que ver con la primacía del poder legislativo sobre el poder ejecutivo, en general, y sobre la economía política, en particular. La segunda se refiere, de forma más específica, a la economía política popular.

Vayamos con la primera. Aunque no lo diga de forma expresa, todo indica que Robespierre está de acuerdo con Rousseau en que la economía política es el corazón, y solamente las leyes son el cerebro. Esto es: la política económica de la nación, en tanto que parte del poder ejecutivo, debe estar subordinada al poder legislativo. Es cierto que Robespierre no lo afirma con esta claridad en su discurso, pero no lo es menos que: a) la desconfianza hacia 
el poder ejecutivo (sea o no monárquico) y su control por parte del poder legislativo es una constante en sus intervenciones (véase Bosc, 2019, 56); b) en su discurso sobre las subsistencias, pronunciado en diciembre de 1792, Robespierre afirma claramente que el principio de la soberanía popular impele al legislador a modificar la economía política heredada del Antiguo Régimen, añadiendo, a continuación, que la primera ley social debe ser aquella que garantiza a todos los miembros de la sociedad el derecho natural a la existencia (Robespierre, 1958 [1792], 9, 110-112).

Desde el momento en que los objetivos fundamentales de la comunidad política no los establecen las voluntades de unos pocos notables, sino que consisten en la garantía de los derechos de todos, la ciencia nueva de la economía política, nacida para aconsejar a esos notables, debe cambiar algunos de sus postulados. Ahora que el soberano es el pueblo en su conjunto, la economía tendrá que empezar a pensar más en cómo asegurar el sustento a todos, y menos en cómo obtener beneficios para los comerciantes. Los productos de primera necesidad deben estar al alcance de todos los hombres. De forma significativa, Robespierre se hace eco - en el mencionado discurso de 1792 - de la metáfora de Rousseau: las subsistencias son la sangre del pueblo, y esta debe fluir libremente por todo el cuerpo social, en lugar que quedar obstruida (léase acaparada) en una parte del mismo (Robespierre, 1958 [1792], 9, 114).

Sentada esta tesis - Robespierre comparte con Rousseau la subordinación de la economía pública, y del poder ejecutivo de la que aquella forma parte, al poder legislativo-, queda todavía por decidir aquello que el ginebrino no ha "creído necesario examinar seriamente". La economía debe estar subordinada a la voluntad general, de acuerdo, pero ¿su diseño debe ser obra exclusiva de los magistrados o es una tarea que también debe corresponder al pueblo? ¿Una economía política subordinada a las leyes puede ser tiránica, puede ser delegada en los déspotas? ¿O esa subordinación solamente es posible a través de una economía política popular? La razón nos dice que esta clase de economía solamente puede ser popular, afirma Rousseau, aunque las cosas se hayan resuelto de otra manera en la práctica.

Robespierre afirma que este problema, que permanecía incierto, se resuelve cuando la República crea las condiciones para que el pueblo pueda deliberar libremente, y sobre cualquier cuestión, en la esfera pública. Es decir: la Revolución es una oportunidad para llevar a la práctica una economía política popular: basada en la deliberación pública y subordinada a la ley. Esta es, para Robespierre, la única economía compatible con una República democrática, que a su vez es el único sistema político capaz de asegurar los derechos naturales a la existencia y a la libertad. Se trata, en definitiva, de que no exista ningún poder público - ni el legislativo, ni (sobre todo) el ejecutivo - que no esté sustentado en el control de los magistrados por parte del pueblo, para así garantizar la unidad de intereses entre los unos y el otro. ¿No creará esto desórdenes?

Se me preguntará, quizás, cómo puedo asegurar la obediencia a las leyes y al gobierno con precauciones tan firmes contra los magistrados. Respondo que la aseguro mucho más, gracias, precisamente, a estas precauciones. Devuelvo a las leyes y al gobierno toda la fuerza que arrebato a los vicios de los hombres que gobiernan y que hacen las leyes (Robespierre, 1958 [1793], 9, 507-508). 
La nueva comunidad política debe intentar acercarse a ese viejo ideal de gobierno de las leyes y no de los hombres. Expresado en los términos actualizados de la Revolución Francesa, se trata de constituir una República basada en la garantía de los derechos del hombre, la cual solamente es posible cuando: a) los gobernantes no actúan al margen de los gobernados, en una esfera que estos últimos no pueden controlar; b) la República se dota de buenas leyes, siendo estas - y no los intereses particulares de una minoría - las que realmente gobiernan la sociedad. Robespierre concluye su discurso con estas bellas palabras:

Legisladores, haced leyes justas. Magistrados, hacedlas ejecutar religiosamente. Que esta sea toda vuestra política, y daréis al mundo un espectáculo desconocido: el de un gran pueblo libre y virtuoso (Robespierre, 1958 [1793], 9, 508).

Propone, a continuación, su proyecto de Constitución. Significativamente, tiene tan solo veinte artículos: es más breve que su proyecto de Declaración de derechos.

\section{Conclusión}

A pesar de haber sido pronunciado en una coyuntura muy específica, creo que el discurso de Robespierre sobre la Constitución nos permite extraer dos lecciones importantes para nuestro presente. La primera tiene que ver, de forma más clara, con la representación política, mientras que la segunda se refiere a la autonomía creciente que han adquirido en nuestra sociedad los "magistrados" encargados de la política económica.

Vayamos con la primera cuestión. Uno de los movimientos sociales más importantes de los últimos años hizo de la representación política uno de sus temas centrales, denunciando la lejanía existente entre los políticos electos y la ciudadanía: "No nos representan". Desgraciadamente, y a pesar del gran impulso democratizador que supuso dicho movimiento, en ciertas ocasiones la denuncia de esta lejanía estuvo excesivamente centrada en lo anecdótico - en aquello que solamente tiene valor en tanto que síntoma de algo más profundo, pero no por sí mismo - , y por lo tanto no dio lugar a un verdadero debate sobre cuál es la mejor forma de entender la representación política en una democracia. Por decirlo de forma sencilla: a veces se puso más atención en el sueldo de los políticos, o en si estos viajaban o no en primera, que en si eran controlables por la ciudadanía. Me parece que una de las cosas que nos enseña el discurso de Robespierre es que el problema de fondo no es si los representantes públicos se parecen o no a los ciudadanos, sino en si existen los mecanismos institucionales suficientes para obligarles a ser del pueblo: a ser amigos del pueblo, como Marat, y no simplemente tribunos del pueblo.

Ocupémonos ahora del segundo punto. La primacía del poder ejecutivo sobre el parlamento no es una novedad de los últimos años, pero seguramente sí que se ha agudizado la autonomía relativa, dentro del primero, de los responsables de la política económica. En nuestro contexto europeo, la frecuencia de sus viajes al norte - si las cosas van bien - y de sus viajes al sur - si las cosas van mal - es buena muestra de que hace tiempo que se han sentado en el cerebro, al lado de las leyes, y de que sus funciones van mucho más allá de asegurar que la sangre llegue al conjunto del cuerpo social. La pregunta que debemos hacernos es si esta clase de política económica es compatible con una sociedad democrática. 
El discurso de Robespierre nos recuerda que la única forma de que la economía no mande sobre las leyes es no dejarla en manos de los expertos en la materia, pues no podemos tener garantías suficientes de que estos - a pesar de su mayor capacidad, e incluso de sus buenas intenciones - vayan a anteponer la garantía de los derechos de todos a los intereses de una minoría.

Creo que merece la pena, pues, que leamos a Robespierre, y que pensemos desde él nuestro presente. No solo porque -como decía el ilustre político- la democracia es el menos malo de todos los sistemas políticos, sino también porque - como decía el ilustre poeta - se ha demostrado que en España (y podemos sospechar que en cualquier otro sitio) lo mejor es el pueblo.

\section{Referencias}

Bosc, Y. (2019), Le peuple souverain et la démocratie. Politique de Robespierre, París: Éditions Critiques.

Diderot, D. (1995), Cuvres de Diderot. Tome III. Politique, edición de L. Versini, París: Robert Laffont.

Domènech, A. (2009), "Droit, droit naturel et tradition républicaine moderne”, en: Belissa, M., Bosc, Y. y Gauthier, F. (eds.): Républicanismes et droit naturel. Des humanistes aux révolutions des droits de l’homme et du citoyen, París: Kimé, pp. 17-30.

Domènech, A. (2015), “Socialismo: ¿De dónde vino? ¿Qué quiso? ¿Qué logró? ¿Qué puede seguir queriendo y logrando?”, en: Bunge, M. y Gabetta, C. (eds.): ¿Tiene porvenir el socialismo?, Barcelona: Gedisa, pp. 71-124.

Encyclopédie (1755), véase la Édition Numérique, Collaborative et CRitique de l'Encyclopédie (ENCCRE): http://enccre.academie-sciences.fr/encyclopedie.

García Manrique, R. (2001), "Sentido y contenido de la Declaración de 1789 y textos posteriores", en: Peces-Barba, G., Fernández, E. y Asís, R. (de) (eds.): Historia de los Derechos Fundamentales. Tomo II. Volumen III, Madrid: Dykinson, pp. 217-394.

Gauthier, F. e Ikni, G.-R. (ed.) (1988), La guerre du blé au XVIIIème siècle, textos de E. P. Thompson, V. Bertrand, C. A. Bouton, F. Gauthier, D. Hunt y G.-R. Ikni, Montreuil: Les Éditions de la Passion.

Geffroy, A. (1989), "Le peuple selon Robespierre”, en: AA. VV.: Permanences de la Révolution : pour un autre bicentenaire, Montreuil: La Brèche-PEC, pp. 179-193.

Labica, G. (2005), Robespierre. Una política de la filosofía, Barcelona: El Viejo Topo.

Laín, B. (2020), "Del derecho natural al pacto fiduciario: gobierno y propiedad en la economía política republicana", Isegoría, 62, pp. 9-34.

Máiz, R. (2007), Nación y revolución: La teoría política de Emmanuel Sieyès, Madrid: Tecnos.

Montesquieu (1824), De l'esprit des lois, en cuatro tomos, París: Madamme Veuve Dabo.

Mundó, J. (2017), "La constitución fiduciaria de la libertad política. (Por qué son importantes las coyunturas interpretativas en la filosofía política)”, Isegoría, 57, pp. 433-454.

Robespierre, M. (1952), Euvres complètes de Maximilien Robespierre. Tome VII : Discours (2ème partie, Janvier - Septembre 1791), editado por la VI Section de l'École des Hautes 
Etudes y la Société des Études Robespierristes, a cargo de M. Bouloiseau, G. Lefebvre y A. Soboul, París: Presses Universitaires de France.

Robespierre, M. (1954), Euvres complètes de Maximilien Robespierre. Tome VIII : Discours (3ème partie, Octobre 1791 - Septembre 1792), editado por la VI Section de l'École des Hautes Etudes y la Société des Études Robespierristes, a cargo de M. Bouloiseau, G. Lefebvre y A. Soboul, París: Presses Universitaires de France.

Robespierre, M. (1958), Euvres de Maximilien Robespierre. Tome IX : Discours (4ème Partie. Septembre 1792 - Juillet 1793), editado por la VI Section de l'École des Hautes Etudes y la Société des Études Robespierristes, a cargo de M. Bouloiseau, G. Lefebvre, J. Dautry y A. Soboul, París: Presses Universitaires de France.

Robespierre, M. (2007), Cuvres complètes de Maximilien Robespierre. Tome XI : Compléments (1784-1794), a cargo de F. Gauthier, París: Société des Études Robespierristes.

Rudé, G. (1976), Robespierre. Portrait of a Revolutionary Democrat, Nueva York: The Viking Press.

Sieyes, E.-J. (1789a), Préliminaire de la Constitution françoise. Reconnoissance et exposition raisonnée des Droits de l'Homme et du Citoyen, París: Baudouin.

Sieyes, E.-J. (1789b), Vues sur les moyens d'exécution dont les représentants de la France pourront disposer en 1789, sin lugar de edición ni editorial.

Sieyes, E.-J. (1970), Qu'est-ce que le Tiers état?, edición crítica a cargo de R. Zapperi, Ginebra: Librairie Droz.

Sieyes, E.-J. (1985), Écrits politiques, edición y presentación de R. Zapperi, Bruselas: Éditions des Archives Contemporaines.

Spinoza, B. (2013), Tratado político, edición de A. Domínguez, Madrid: Alianza Editorial. 